\title{
Potentiality of gluten-free chocolate cookies with added inulin/ oligofructose: Chemical, physical and sensory characterization
}

\author{
Tatiane Ferreira da Silva, Ana Carolina Conti-Silva* \\ São Paulo State University (Unesp), Institute of Biosciences, Humanities and Exact Sciences (Ibilce), Campus São José do Rio Preto, Department of Food Engineering and \\ Technology, Rua Cristóvão Colombo, 2265, CEP 15054-000, São José do Rio Preto, SP, Brazil
}

\section{A R T I C L E I N F O}

\section{Keywords:}

\section{Celiac}

Fructans

Sensory acceptance

Sensory profile

External preference mapping

\begin{abstract}
A B S T R A C T
Looking to supply a gluten-free product with improved acceptance, and that promote a possible increase in the absorption of calcium in individuals with celiac disease, gluten-free chocolate cookies with oligofructose-enriched inulin added as a partial substitute for rice flour in the proportions of 25, 50 and 75\% were characterized chemically, physically and sensorially. The chocolate cookie with $25 \%$ substitution of rice flour by inulin/oligofructose was as well accepted as the chocolate cookie with $100 \%$ rice flour (control) and the commercial cookie for most sensory properties and intention of purchase. This acceptance was resultant from high intensities of the descriptor terms grittiness, fracturability, yellow and red chromaticities and specific volume, in addition to the low intensities of caramel aroma, caramel flavor, brightness, adhesiveness, chewiness, sweet taste and hardness, and the low instrumental cutting force. Also, all the chocolate cookies may be claimed as gluten-free products. Considering a daily consumption of 3, 2 and 1 servings of gluten-free chocolate cookies with rice flour substitution by 25,50 and $75 \%$ of inulin/oligofructose respectively, the recommended ingestion of $8 \mathrm{~g}$ per day of inulin/oligofructose for enhancing calcium absorption is reached.
\end{abstract}

\section{Introduction}

Celiac disease is an autoimmune disease activated in genetically susceptible individuals through food exposure to gluten and it is characterized by villous atrophy and inflammation of the small intestine in celiac patients, which causes damage to the mucosa and generalized malabsorption of nutrients (Sapone et al., 2012). The only treatment of the disease is the strict adherence to a gluten-free diet, since diet gluten deprivation leads to cessation of symptoms and partial restoration of histological damage. Patients who avoid gluten usually experience improved symptoms with healing of the intestinal mucosa, while the reinstallation of gluten causes a relapse on them (Ciacci et al., 2015; Panteris \& Karamanolis, 2005).

Celiac disease is also related to bone disorders that occur both due to low intake of calcium and vitamin $\mathrm{D}$, as a result of the poor nutritional quality of gluten-free foods, and also due to malabsorption of these nutrients due to the disease itself (Kamycheva, Goto, \& Camargo, 2016). Therefore, the ingestion of fructans, such as inulin and oligofructose, has been investigated as a resource for increasing calcium absorption and bone mineral density. However, the application of fructans in food products aiming the increase of calcium absorption is still limited (Capriles \& Arêas, 2013; Capriles, Soares, Pinto e Silva, \&
Arêas, 2009), since its application in foods is mainly focused with fiber and prebiotic functions, and as supplement (Shoaib et al., 2016).

Studies performed in teenagers and young adults have shown the potential of supplemented inulin and oligofructose for improving calcium absorption. The ingestion of $8 \mathrm{~g}$ per day of oligofructose-enriched inulin (Raftilose Synergy1, Orafti) resulted in higher calcium absorption in relation to individuals that received a placebo of sucrose (Griffin, Davila, \& Abrams, 2002; Griffin, Hicks, Heaney, \& Abrams, 2003), or a placebo of maltodextrin (Abrams et al., 2005). Abrams et al. (2007), in a study with Beneo Synergy1 (Orafti), also pointed out that the fructan benefits are especially important when absorption in the small intestine is reduced for anatomic and physiological reasons. Therefore the consumption of fructans by individuals with celiac may be important for relieving the damage resultant from the pathology.

Among gluten-free products, biscuits stand out as being an important cereal-based product (Jothi, Hashem, Rana, Rahman, \& ShamsUd-Din, 2014), because they are popular widely-consumed bakery items, they are practical, can be eaten anywhere, have good nutritional quality and are available in different varieties and at an affordable cost (Laguna, Salvador, Sanz, \& Fiszman, 2011). Most bakery products can be used as a vehicle for incorporating different ingredients of high nutritional value (Sudha, Vetrimani, \& Leelavathi, 2007) and the

\footnotetext{
* Corresponding author.

E-mail address: contisil@ibilce.unesp.br (A.C. Conti-Silva).
} 
addition of fructan is viable in this type of product. However, the addition of fructans results in changes in the sensory attributes of different products (Franck, 2002; Volpini-Rapina, Sokei, \& Conti-Silva, 2012; Wang, 2009), so investigating the effects of fructans on the sensory characteristics of cookies is fundamental. In this sense, using the appropriate methodology, through the personal response of the consumers, or through evaluators that describe the sensorial profile, sensory research can provide information about those products evaluated through the complex interaction of the senses (Tuorila \& Monteleone, 2009).

Therefore, looking to supply a gluten-free product with high nutritive value and improved acceptance, the aim of this research was to develop gluten-free chocolate cookies, with sufficient added inulin/ oligofructose to promote a possible increase in the absorption of calcium in individuals with celiac, as well as characterization of the products.

\section{Material and methods}

\subsection{Material}

The product Orafti ${ }^{\circledR}$ Synergy 1 was provided by Beneo. According to the company, this product is oligofructose-enriched inulin and it contains approximately $92 \%$ of inulin with a dedicated combination of longer and shorter chains to achieve specific physiological effects (BENEO, 2016a). This ingredient has been found to be particularly efficient in enhancing the bioavailability of calcium in the diet and support calcium absorption (BENEO, 2016b). In this research, this ingredient is called inulin/oligofructose.

The other ingredients used for the cookie production were: rice flour (Urbano), refined sugar (União), unsalted butter (Aviação), egg (Iwamoto), cocoa powder (Nestlé), vanilla extract (Dr. Oetker), baking powder (Royal) and salt (Cisne). All the ingredients were purchased from a local market.

Moreover, a chocolate-flavored commercial cookie was also purchased in the local market to be compared to the cookies made for the study. The list of ingredients of this cookie included organic wheat flour enriched with iron and folic acid, organic sugar, organic palm oil, organic cocoa, invert sugar, salt, chemical leavening (ammonium bicarbonate and sodium bicarbonate), and natural vanilla aroma. It was not purchased a gluten-free commercial chocolate cookie due to the lack of this kind of product in the local market.

\subsection{Cookie production}

Gluten-free chocolate cookies were developed based on an adaptation from Silva and Conti-Silva (2016), which showed that rice flour constitutes the most suitable substitute for wheat flour in this product. Therefore, the standard formulation with rice flour was produced using the same ingredients and procedures described in the above research, excluding the sodium bicarbonate (Supplementary Table 1).

The cookies with inulin/oligofructose added had the rice flour replaced by 25, 50 and 75\% Orafti ${ }^{\oplus}$ Synergy 1 (Supplementary Table 1), or, in other words, 9.4, 18.8 and $28.3 \%$ inulin/oligofructose in $100 \%$ of dough. The amounts of the remaining ingredients (section 2.1) and the preparation were identical to those of the standard cookie described in Silva and Conti-Silva (2016).

\subsection{Analysis of the chemical characteristics of cookies}

The cookies were characterized regarding their chemical composition, as follows: moisture content based on evaporation at $105{ }^{\circ} \mathrm{C}$, protein content using the micro-Kjeldahl method, lipid content using the extraction method by Soxhlet with petroleum ether and ash by incineration in a muffle furnace at $550{ }^{\circ} \mathrm{C}$ (AOAC, 1990), fiber content using the enzymatic-gravimetric method described by Prosky, Asp,
Schweizer, DeVries, and Furda (1988), and total fructans according to McCleary and Rossiter (2004). The available carbohydrates were calculated as the percentage difference between 100 and the sum of the moisture, protein, lipid, ash and total dietary fibers percentages. All analyses were performed in triplicate, except for the fiber (duplicate).

Gluten analysis was also performed, through antigen-antibody reaction, performed on ELISA microtiter plates with wells sensitized with anti-gliadin R5 (RIDASCREEN Gliadin R-Biopharm, Darmstadt, Germany). The absorbance reading was made at $450 \mathrm{~nm}$, using an ELISA ELX800 reader (Biotek Instruments), and a standard curve for gliadin was used for the final calculation.

\subsection{Analysis of the physical properties of cookies}

The color of four random cookies was analyzed using a Hunterlab colorimeter, model Color Flex 45/0 (Reston, USA) and the Spectra Magic Nx program (CM-S100W version 2.03.0006, Virginia, USA), as well as with D65 illuminant and a $10^{\circ}$ observer angle. The CIE-L*a*b* system was used (luminosity $=L^{*}, a^{*}=$ red/green, $b^{*}=$ yellow/blue) and the chroma value $\left(\mathrm{C}^{*}\right)$ and hue $(\mathrm{h})$ were also obtained.

The instrumental texture was evaluated using a TA.XT/Plus/50 Texture Analyser (Stable Micro Systems, Godalming, England) and the Texture Exponent 32 software (Stable Micro Systems, Godalming, England). The three-point bending probe with a distance of $3.0 \mathrm{~cm}$ between the edges and a test speed of $1.0 \mathrm{~mm} \mathrm{~s}^{-1}$, was used (Laguna, Varela, Salvador, Sanz, \& Fiszman, 2012). Ten random cookies were compressed until they broke completely and the maximum force obtained was defined as the cutting force of the cookies.

The specific volume $\left(\mathrm{cm}^{3} \cdot \mathrm{g}^{-1}\right)$ was measured according to the AACC (2000), and the expansion factor, defined as FE $=$ (diameter/thickness of the cookie after baking)/(diameter/thickness of the cookie before baking) was also evaluated according to AACC (2000). Ten random samples were evaluated.

\subsection{Analysis of the sensory profile of cookies}

This study was approved by the Research Ethics Committee at the Institute of Biosciences, Humanities and Exact Sciences, at Sao Paulo State University (Unesp) (Decision 149.493). The cookies were evaluated for the sensory profile using the descriptive analysis adapted from Stone and Sidel (2004).

Panelists were recruited among undergraduate and postgraduate students from the above Institute. Fifteen panelists, out of the thirty-one recruited, were preselected through a basic taste recognition, an odor recognition test and a difference-from-control test with a nine-point scale for a hardness parameter. For this last one test, the cookie with no substitution of rice flour was set as the control sample, and compared to cookies with substitution of rice flour by 25,50 and $75 \%$ inulin/oligofructose, due to the differences on intensities of the hardness among the cookies.

The sensory attributes were generated by the fifteen panelists, using the Kelly Repertory Grid method (Moskowitz, 1983). After discussions to reach a consensus, the descriptive terms that were most important for characterizing the appearance, aroma, texture and flavor of the cookies were selected. The sensory panel also defined the descriptor terms and the references for each of these (Supplementary Table 2).

In the training stage, that lasted ten sessions of $30 \mathrm{~min}$ each, the panelists analyzed the chocolate cookies, using the definitions and references previously developed, as well, the evaluation form. The training sessions were thus directed to develop the sensory memorization of the descriptor terms and references by the sensory panel, and only in the last training session, the samples were evaluated in individual booths under white light.

After the training stage, the panelists were selected according to their capacity to discriminate samples $\left(\mathrm{p}_{\text {sample }} \leq 0.50\right.$ ), capacity to reproduce judgments (prepetition $>0.05$ ) and consensus with the panel 
(Damásio \& Costell, 1991), and twelve panelists were selected to analyze the sensory profile of the cookies. The sensory panel consisted of a majority of females (92\%), with ages ranging from 23 to 47 years old, all nonsmokers. Regarding the habits related to cookies, $75 \%$ of the panelists like them very much and all of them consume cookies: $8.3 \%$ three times a week, $50 \%$ once a week and $48.7 \%$ occasionally.

The sensory analysis was performed in individual booths, under white light and at a temperature of $22^{\circ} \mathrm{C}$. The cookies were presented on white napkins coded with three-digit random numbers and were evaluated in three repetitions by the twelve panelists. The sample presentation was balanced in complete blocks (MacFie, Bratchell, Greenhoff, \& Vallis, 1989), they were presented in a monadic way and an unstructured linear intensity scale of $90 \mathrm{~mm}$ length was used for each descriptor. A glass with water at room temperature was served to panelists to drink between samples.

\subsection{Analysis of the sensory acceptance of cookies}

The acceptance analysis was performed in individual booths under white light and at a temperature of $22{ }^{\circ} \mathrm{C}$. One hundred and ten consumers were recruited from students, staff and professors of the Institute. Initially, a questionnaire was applied to characterize consumers. Then, cookies were evaluated using the nine-point structured hedonic scale, with the extremes " 1 - dislike extremely " and " 9 - like extremely" for appearance, aroma, texture and flavor, as well as overall acceptance and the five-point scale for purchase intention, which ranged from "I would certainly not buy this" to "I would certainly buy this" (Meilgaard, Civille, \& Carr, 2007). Cookies were presented in a monadic and balanced way and in complete block (MacFie et al., 1989), and each consumer received the sample on a three-digit coded napkin and a glass with water at room temperature to drink between samples.

Consumers were not celiac, because the commercial chocolate cookie is made with wheat flour (section 2.1). Moreover, a study comparing the sensory and hedonic perception between celiac and nonceliac subjects of gluten-free breads showed no difference between the two groups in the description and perception in relation to the sensory characteristics of the products (Laureati, Giussani, \& Pagliarini, et al., 2012).

\subsection{Statistical analyses}

The medians for the chemical and physical parameters were compared using the Kruskal-Wallis test followed by the Dunn test, while the means related to the sensory analysis were compared through analysis of variance followed by the Tukey test, all analyses at a significance level of 0.05 . Two external preference maps were constructed using principal component analysis: one correlating sensory acceptance and descriptive terms; and another correlating sensory acceptance and physical parameters. The variables were placed in the columns and the cookies were placed in the rows, and the data were standardized in the columns before the analysis. Factor extraction was performed from the correlation matrix and factor rotation was not used. All analyses were performed using the Statistica 10.0 software (StatSoft, Inc.).

The PLS (partial least square) analysis was also performed to cookie data, considering the overall acceptance as dependent variables and both the descriptor terms and physical parameters as the explanatory (independent) variables. The analysis was performed using the XLSTAT statistical software for Microsoft Excel.

\section{Results and discussion}

\subsection{Chemical characterization of cookies}

The moisture, ash, lipid, proteins, insoluble fiber and soluble fiber contents were, in general, similar among all the cookies, except to the commercial one (Table 1). Apparently, there was a decrease in the available carbohydrate content and an increase in the total dietary fiber content of the control cookie, followed by the cookies with substitution of $25 \%, 50 \%$ and $75 \%$ of the rice flour by inulin/oligofructose due to the increased substitution. In addition, the cookie with $75 \%$ inulin/ oligofructose had higher soluble fiber, insoluble fiber and total fructan content than the $25 \%$ cookie.

Considering a $30 \mathrm{~g}$ servings (Brasil, 2003), the cookies with substitution of $25 \%, 50 \%$ and $75 \%$ of the rice flour by inulin/oligofructose provide respectively $4.6,10.9$ and $13.9 \mathrm{~g} / 100 \mathrm{~g}$ of total dietary fiber, and may be described respectively as "source", "high content" and "high content" of fiber according to Brasil (2012), as "low", "high" and "high" in dietary fiber according to Food and Drug Administration (2017), and all as "high" in fiber according to European Commission (2017). Also, the consumption of 3, 2 and 1 servings of the cookies with $25 \%, 50 \%$ and $75 \%$ substitution of rice flour by inulin/oligofructose, respectively, may contribute to the increasing of calcium absorption, according to the literature (Abrams et al., 2005, 2007; Griffin et al., 2002; Griffin et al., 2003). Moreover, according to the Codex Alimentarius Commission (2008), control cookies and with inulin/oligofructose may be considered "gluten-free" since they contain gluten levels below $20 \mathrm{ppm}$.

\subsection{Physical characterization of cookies}

The cookie with $50 \%$ substitution of the rice flour by inulin/oligofructose showed higher luminosity (L *) among all the cookies, indicating a lighter color, and all the cookies presented red and yellow chromaticities (positive values of $\mathrm{a}^{*}$ and $\mathrm{b}^{*}$, respectively) (Table 2). In general, the red chromaticity was similar among all the cookies, and the inulin/oligofructose cookies stood out by lower yellow chromaticity and higher color saturation $\left(\mathrm{C}^{*}\right)$ than the commercial cookie. The cookie with $25 \%$ substitution of rice flour by inulin/oligofructose had the same hue in relation to the commercial cookie, but different from the other cookies with inulin/oligofructose. In spite of the recognized effect of the fructans on the color of the products, favoring the Maillard reaction because of the reducing sugars in their chain, the results for the color attributes did not follow any definite pattern with the increase in the substitution of the rice flour by the inulin/oligofructose.

Regarding the cutting force, the cookies with inulin/oligofructose had higher values than the control cookie, but they were similar to the commercial cookie (Table 2). According to Pareyt, Brijs, and Delcour (2010), biscuits with high sugar content may present higher hardness due to the crystallization of the sugar during its cooling. Although the amount of sugar was the same for all but the commercial cookies, it is likely that the added inulin/oligofructose resulted in a higher cutting force due to fructose crystallization.

The cookie with $25 \%$ substitution of rice flour by inulin/oligofructose presented higher specific volume than the commercial cookie, and was statistically similar to the control cookie, while cookies with 50 and $75 \%$ substitution of rice flour by inulin/oligofructose had a smaller specific volume than the control (Table 2). In relation to the expansion factor, the cookies with $25 \%$ and $50 \%$ substitution have expanded more than the control. Maache-Rezzoug, Bouvier, Allaf, and Patras (1998) studied the influence of water, fats and sucrose on biscuit doughs and concluded that sugar granules with smaller granulometry and in high concentration contribute to the spreadability of dough. Thus, the higher amount of fructose in cookies with inulin/oligofructose may explain the fact that these cookies had a higher expansion factor than the control cookie, with the exception of the cookie with $75 \%$ substitution of rice flour by inulin/oligofructose, which should not have expanded so much due to increased caramelization during the baking.

\subsection{Sensory profile of cookies}

The cookies with inulin/oligofructose showed higher brightness, caramel aroma, hardness, adhesiveness, chewiness, sweet taste and 
Table 1

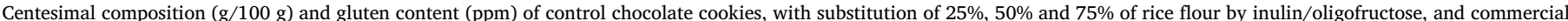
(mean \pm standard deviation; $\mathrm{n}=3 ; \mathrm{n}=2$ for fiber).

\begin{tabular}{|c|c|c|c|c|c|}
\hline Chemical characteristics & Control & $25 \%$ & $50 \%$ & $75 \%$ & Commercial \\
\hline Moisture & $5.1 \pm 0.1^{\mathrm{b}}$ & $5.7 \pm 0.0^{\mathrm{ab}}$ & $5.9 \pm 0.1^{\mathrm{ab}}$ & $6.4 \pm 0.1^{\mathrm{a}}$ & $3.5 \pm 0.1$ \\
\hline Ash & $1.7 \pm 0.0^{\mathrm{ns}}$ & $1.7 \pm 0.0^{\mathrm{ns}}$ & $1.6 \pm 0.1^{\mathrm{ns}}$ & $1.5 \pm 0.1^{\mathrm{ns}}$ & $1.1 \pm 0.1$ \\
\hline Lipids & $14.2 \pm 0.2^{\mathrm{a}}$ & $13.8 \pm 0.0^{\mathrm{ab}}$ & $12.1 \pm 0.3^{\mathrm{ab}}$ & $9.4 \pm 0.1^{\mathrm{b}}$ & $21.3^{\mathrm{c}}$ \\
\hline Proteins & $6.1 \pm 0.0^{\mathrm{a}}$ & $5.2 \pm 0.2^{\mathrm{ab}}$ & $4.7 \pm 0.1^{\mathrm{ab}}$ & $3.8 \pm 0.0^{\mathrm{b}}$ & $7.0^{c}$ \\
\hline Total Dietary Fiber ${ }^{\mathrm{a}}$ & 4.2 & 15.3 & 36.2 & 46.3 & $3.0^{\mathrm{c}}$ \\
\hline Insoluble fibers & $4.2 \pm 0.0^{\mathrm{ab}}$ & $4.1 \pm 0.1^{\mathrm{b}}$ & $4.5 \pm 0.1^{\mathrm{ab}}$ & $4.7 \pm 0.2^{\mathrm{a}}$ & n.a. \\
\hline Soluble fibers & $0.0 \pm 0.0$ & $0.2 \pm 0.0^{\mathrm{b}}$ & $13.2 \pm 0.4^{\mathrm{ab}}$ & $14.2 \pm 0.7^{\mathrm{a}}$ & n.a. \\
\hline Total fructans & n.d. & $11.0 \pm 0.1^{\mathrm{b}}$ & $18.5 \pm 0.5^{\mathrm{ab}}$ & $27.4 \pm 0.2^{\mathrm{a}}$ & n.a. \\
\hline Carbohydrates available $^{\mathrm{b}}$ & 68.7 & 58.3 & 39.5 & 32.6 & 64.1 \\
\hline Gluten & $<5$ & $<5$ & $<5$ & $<5$ & $0.3 \pm 0.0$ \\
\hline
\end{tabular}

Different letters in the same line indicate statistical difference by the Dunn test ( $\mathrm{p} \leq .05$ ).

$\mathrm{ns}=$ not significant.

n.d. $=$ Not determined due to non-use of inulin/oligofructose in this formulation.

n.a. = Not available.

${ }^{\text {a }}$ Sum of insoluble fiber, soluble fiber and total fructans.

${ }^{\mathrm{b}}$ Resultant from 100 - (moisture + ash + lipids + proteins + total dietary fiber).

${ }^{c}$ Information provided on the label.

caramel flavor compared to control and commercial cookies (Table 3). According to Huebner, Wehling, Parkhurst, and Hutkins (2008), during the baking the Maillard reaction occurs, in which the reducing sugars present in the fructan chains react with amino acids, producing compounds of higher molecular weight that may influence the flavor, aroma and color of the food. In this case, the increased intensities of brightness, caramel aroma and flavor may have been due to the Maillard reaction. Furthermore, such a reaction may also have contributed to the increased brown color over the control cookie.

According to BENEO (2016a), Orafti Synergy1 is composed of oligofructose-enriched inulins, substances that are polymers of fructose linked by linear or branched connections through $\beta(2 \rightarrow 1)$ or $\beta(2 \rightarrow 6)$ (Carabin \& Flamm, 1999; Morris \& Morris, 2012). Inulin produces a mild neutral flavor while oligofructose is moderately sweet, with a sweetness power near to that of sugar (Franck, 2002). Therefore, the substitution of rice flour by this product may have contributed to the higher intensity of sweet taste in the cookies (Table 3). RodriguezGarcia, Laguna, Puig, and Hernando (2013) also found higher sweetness, measured by a non-trained sensory panel, in biscuits that had the fat replaced by inulin.

The fructans are soluble fibers. Indeed, it is to be expected that the fibers influence the texture of foods (Pomeranz, Shogren, Finney, \& Bechtel, 1977; Wang, Rosell, \& Barber, 2002), in addition to which soluble fibers can absorb water during the preparation of a product (Ronkart, Paquot, Fougnies, Deroanne, \& Blecker, 2009). These factors justify the increase in hardness, adhesiveness and chewiness of cookies with inulin/oligofructose (Table 3). Other studies have observed similar effects of fructans on these characteristics for sugar-free sponge cakes with nondigestible oligosaccharides (Ronda, Gómez, Blanco, \&
Caballero, 2005), orange cakes with inulin and inulin/oligofructose (Volpini-Rapina et al., 2012), biscuits with inulin (Błońska, Marzec, \& Błaszczyk, 2014), and gluten-free chocolate cookies with whole soy flour (Silva \& Conti-Silva, 2016).

The increase in inulin/oligofructose concentration resulted in less fracturable and less gritty cookies (Table 3). Brennan and Samyue (2004) reported that the addition of dietary fiber to biscuit affected shrinkage and height development during baking, reducing the resistance of biscuits to fracture during texture analysis tests. Handa, Goomer, and Siddhu (2011) also observed the reduction of the gritty texture of cookies produced with finger millet and sorghum grain through the use of soluble fiber, such as inulin/fructooligosaccharides.

The chocolate aroma and flavor were less intense in the control cookies and with olifrogructose/inulin in relation to the commercial ones, being even less in the cookies with the fructans (Table 3). The lesser intensities in these terms can be justified by the prevalence of a caramel aroma and flavor in the cookies developed in this study. Tárrega and Costell (2006) reported that inulin increased thickness and creaminess (texture attributes), and sweetness and vanilla flavor (taste and aroma attributes) in fat-free starch-based dairy desserts, especially in samples with low starch concentrations.

\subsection{Sensory acceptance of cookies}

Approximately $85 \%$ of consumers who participated in the sensory analysis were between 18 and 30 years old and the majority were women $(71 \%)$. Around $88 \%$ of consumers like cookies very much, $52 \%$ consume cookies from once a week to daily, and $32 \%$ fortnightly. In general, $75 \%$ of the consumers reported that they prefer traditional

Table 2

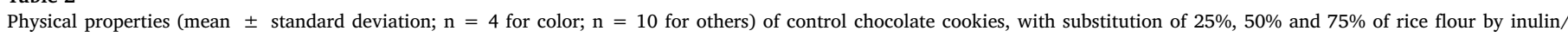
oligofructose, and commercial.

\begin{tabular}{|c|c|c|c|c|c|c|}
\hline \multicolumn{2}{|c|}{ Physical properties } & \multirow{2}{*}{$\begin{array}{l}\text { Control } \\
28.1 \pm 0.7^{\mathrm{b}}\end{array}$} & \multirow{2}{*}{$\begin{array}{l}25 \% \\
27.0 \pm 0.7^{c}\end{array}$} & \multirow{2}{*}{$\begin{array}{l}50 \% \\
28.7 \pm 0.5^{\mathrm{a}}\end{array}$} & \multirow{2}{*}{$\begin{array}{l}75 \% \\
27.9 \pm 0.6^{b}\end{array}$} & \multirow{2}{*}{$\begin{array}{l}\text { Commercial } \\
25.5 \pm 0.7^{\mathrm{c}}\end{array}$} \\
\hline Color & $L^{*}$ & & & & & \\
\hline & $a^{*}$ & $9.7 \pm 0.2^{\mathrm{ab}}$ & $9.8 \pm 0.1^{\mathrm{a}}$ & $9.5 \pm 0.2^{b}$ & $9.3 \pm 0.8^{\mathrm{ab}}$ & $9.7 \pm 0.1^{\mathrm{ab}}$ \\
\hline & $b^{*}$ & $11.8 \pm 0.4^{\mathrm{a}}$ & $10.8 \pm 0.4^{\mathrm{bc}}$ & $10.5 \pm 0.3^{\mathrm{c}}$ & $9.3 \pm 1.1^{\mathrm{d}}$ & $11.4 \pm 0.5^{\mathrm{ab}}$ \\
\hline & $C^{*}$ & $29.7 \pm 0.7^{\mathrm{ab}}$ & $28.8 \pm 0.7^{c}$ & $30.2 \pm 0.5^{\mathrm{a}}$ & $29.4 \pm 0.9^{\mathrm{bc}}$ & $27.3 \pm 0.6^{\mathrm{d}}$ \\
\hline & $\mathrm{H}$ & $19.1 \pm 0.2^{\mathrm{b}}$ & $20.0 \pm 0.3^{\mathrm{a}}$ & $18.4 \pm 0.4^{\mathrm{c}}$ & $18.5 \pm 1.2^{\mathrm{bc}}$ & $20.7 \pm 0.7^{\mathrm{a}}$ \\
\hline & $31.8 \pm 4.4^{\mathrm{c}}$ & $39.5 \pm 4.3^{\mathrm{b}}$ & $42.8 \pm 9.4^{\mathrm{ab}}$ & $49.2 \pm 8.0^{\mathrm{a}}$ & $43.3 \pm 3.8^{\mathrm{ab}}$ \\
\hline \multicolumn{2}{|c|}{ Specific volume $\left(\mathrm{cm}^{3} \cdot \mathrm{g}^{-1}\right)$} & $2.2 \pm 0.1^{\mathrm{ab}}$ & $2.3 \pm 0.1^{\mathrm{a}}$ & $1.8 \pm 0.2^{\mathrm{c}}$ & $1.5 \pm 0.1^{\mathrm{d}}$ & $1.8 \pm 0.1^{\mathrm{bcd}}$ \\
\hline \multicolumn{2}{|c|}{ Expansion factor } & $0.7 \pm 0.0^{c}$ & $0.8 \pm 0.1^{\mathrm{ab}}$ & $0.8 \pm 0.1^{\mathrm{a}}$ & $0.7 \pm 0.0^{\mathrm{bc}}$ & n.d. \\
\hline
\end{tabular}

Different letters on the same line indicate statistical difference by the Dunn test ( $\mathrm{p} \leq .05$ ).

n.d. $=$ Not determined due to missing cookie diameter and thickness values before baking. 
Table 3

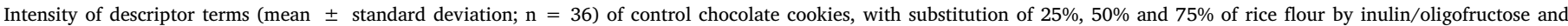
commercial.

\begin{tabular}{|c|c|c|c|c|c|}
\hline Descriptor terms & Control & $25 \%$ & $50 \%$ & $75 \%$ & Commercial \\
\hline Color Brown & $4.0 \pm 1.1^{\mathrm{d}}$ & $5.1 \pm 0.9^{c}$ & $5.3 \pm 0.7^{\mathrm{bc}}$ & $5.8 \pm 1.1^{\mathrm{b}}$ & $6.8 \pm 0.8^{\mathrm{a}}$ \\
\hline Brightness & $1.5 \pm 1.1^{\mathrm{d}}$ & $4.8 \pm 1.4^{\mathrm{c}}$ & $6.2 \pm 1.7^{\mathrm{b}}$ & $7.8 \pm 0.4^{\mathrm{a}}$ & $1.0 \pm 0.5^{\mathrm{d}}$ \\
\hline Caramel aroma & $2.1 \pm 1.8^{\mathrm{d}}$ & $5.9 \pm 1.2^{\mathrm{c}}$ & $6.7 \pm 0.8^{b}$ & $7.5 \pm 0.4^{\mathrm{a}}$ & $1.1 \pm 0.4^{\mathrm{e}}$ \\
\hline Chocolate aroma & $4.4 \pm 1.6^{\mathrm{b}}$ & $2.2 \pm 0.9^{c}$ & $1.8 \pm 0.7^{\mathrm{cd}}$ & $1.5 \pm 0.6^{\mathrm{d}}$ & $6.2 \pm 1.2^{\mathrm{a}}$ \\
\hline Hardness & $3.3 \pm 1.1^{\mathrm{e}}$ & $5.4 \pm 1.4^{\mathrm{c}}$ & $7.0 \pm 1.0^{\mathrm{b}}$ & $7.8 \pm 0.6^{\mathrm{a}}$ & $4.4 \pm 1.2^{\mathrm{d}}$ \\
\hline Adhesiveness & $3.0 \pm 1.2^{\mathrm{d}}$ & $5.1 \pm 1.4^{\mathrm{c}}$ & $6.7 \pm 1.3^{\mathrm{b}}$ & $7.6 \pm 0.4^{\mathrm{a}}$ & $2.3 \pm 1.1^{\mathrm{d}}$ \\
\hline Fracturability & $6.7 \pm 1.0^{\mathrm{a}}$ & $5.6 \pm 1.2^{\mathrm{b}}$ & $3.9 \pm 1.4^{\mathrm{c}}$ & $2.6 \pm 1.1^{\mathrm{d}}$ & $6.8 \pm 0.7^{\mathrm{a}}$ \\
\hline Chewiness & $3.6 \pm 1.1^{\mathrm{d}}$ & $5.2 \pm 1.1^{\mathrm{c}}$ & $6.5 \pm 1.1^{\mathrm{b}}$ & $7.3 \pm 0.5^{\mathrm{a}}$ & $3.5 \pm 0.9^{\mathrm{d}}$ \\
\hline Grittiness & $7.1 \pm 0.6^{\mathrm{a}}$ & $5.8 \pm 1.1^{\mathrm{b}}$ & $3.7 \pm 1.6^{c}$ & $2.3 \pm 1.4^{\mathrm{d}}$ & $6.7 \pm 1.2^{\mathrm{a}}$ \\
\hline Sweet taste & $4.4 \pm 1.4^{\mathrm{e}}$ & $6.1 \pm 0.8^{c}$ & $6.7 \pm 0.7^{b}$ & $7.4 \pm 0.7^{\mathrm{a}}$ & $5.1 \pm 1.1^{\mathrm{d}}$ \\
\hline Caramel flavor & $2.0 \pm 1.3^{\mathrm{d}}$ & $5.7 \pm 1.4^{c}$ & $6.6 \pm 0.8^{\mathrm{b}}$ & $7.4 \pm 0.4^{\mathrm{a}}$ & $1.1 \pm 0.5^{\mathrm{e}}$ \\
\hline Chocolate flavor & $3.4 \pm 1.4^{\mathrm{b}}$ & $2.3 \pm 0.8^{c}$ & $1.8 \pm 0.7^{\mathrm{cd}}$ & $1.6 \pm 0.5^{\mathrm{d}}$ & $5.8 \pm 1.4^{\mathrm{a}}$ \\
\hline
\end{tabular}

Different letters in the same line indicate statistical difference by the Tukey test ( $\mathrm{p} \leq .05)$.

Table 4

Sensory acceptance (mean and significant minimum difference - SMD; $\mathrm{n}=110$ ) of control chocolate cookies, with substitution of $25 \%, 50 \%$ and $75 \%$ of rice flour by inulin/ oligofructose and commercial.

\begin{tabular}{lllllll}
\hline Sensory acceptance & control & $25 \%$ & $50 \%$ & $75 \%$ & Commercial & SMD \\
\hline Appearance & $7.5^{\mathrm{a}}$ & $7.7^{\mathrm{a}}$ & $6.7^{\mathrm{b}}$ & $5.4^{\mathrm{c}}$ & $7.3^{\mathrm{a}}$ & 0.55 \\
Aroma & $7.3^{\mathrm{a}}$ & $7.3^{\mathrm{a}}$ & $6.8^{\mathrm{b}}$ & $6.2^{\mathrm{c}}$ & $6.8^{\mathrm{ab}}$ & 0.54 \\
Texture & $7.5^{\mathrm{a}}$ & $6.8^{\mathrm{b}}$ & $4.7^{\mathrm{c}}$ & $3.1^{\mathrm{d}}$ & $7.6^{\mathrm{a}}$ & 0.58 \\
Flavor & $7.1^{\mathrm{ab}}$ & $7.1^{\mathrm{a}}$ & $6.1^{\mathrm{c}}$ & $5.1^{\mathrm{d}}$ & $6.5^{\mathrm{bc}}$ & 0.61 \\
Overall acceptance & $7.2^{\mathrm{a}}$ & $7.1^{\mathrm{a}}$ & $5.5^{\mathrm{b}}$ & $4.0^{\mathrm{c}}$ & $6.9^{\mathrm{a}}$ & 0.54 \\
Purchase intention & $3.9^{\mathrm{a}}$ & $3.8^{\mathrm{a}}$ & $2.7^{\mathrm{b}}$ & $1.8^{\mathrm{c}}$ & $3.7^{\mathrm{a}}$ & 0.35 \\
\hline
\end{tabular}

Different letters in the same line indicate statistical difference by the Tukey test ( $\mathrm{p} \leq .05$ ).

chocolate cookies with chocolate chips, $30 \%$ prefer chocolate cookies, $21 \%$ prefer wholemeal cookie and $9 \%$ prefer traditional cookies.

The cookie formulated with $25 \%$ substitution of rice flour by inulin/ oligofructose presented the same degree of liking as the rice flour cookie (control) and the commercial cookie for most sensory attributes, overall acceptance and purchase intention, which is a very positive result from the sensory point of view, especially when compared to the commercial one. It also presented a lesser degree of liking for the texture in relation to the commercial cookie, but it presented a greater degree of liking for the flavor in relation to the commercial cookie
(Table 4). The increase in the amount of inulin/oligofructose decreased the acceptance of cookies, reaching rejection means for some attributes of cookies with 50 and $75 \%$ of substitution.

A literature review performed by Ktenioudaki and Gallagher (2012) found that sensory acceptance can be affected by the addition of fiber to baked goods when fiber addition varies between $5 \%$ and $15 \%$. The sensory changes pointed are especially related to appearance, texture and flavor, as decrease on volume, increase of hardness, loss of crispiness, and change on taste and appearance (color, surface properties, and density). Indeed, the acceptance of attributes, as well the overall acceptance, decreased with the increasing of inulin/oligofructose that are soluble fibers and were added from $25 \%$ to $75 \%$. Moreover, considering the increasing on the sweetness and the caramel aroma and flavor of the cookies together with the inulin/oligofructose addition (Table 4), the chocolate aroma and flavor in the cookies reduced, also resulting in lower sensory acceptance because of the decharacterization of the cookies.

The sensory acceptance correlates with the sensory profile of cookies (Fig. 1). The first and second principal components explained, respectively, $81.7 \%$ and $14.3 \%$ of the data variation, with a total of $96.0 \%$. The first principal component was explained by two groups of variables: one composed by all sensory acceptance, grittiness, fracturability, chocolate aroma and chocolate flavor (factorial charges $\geq 0.7$
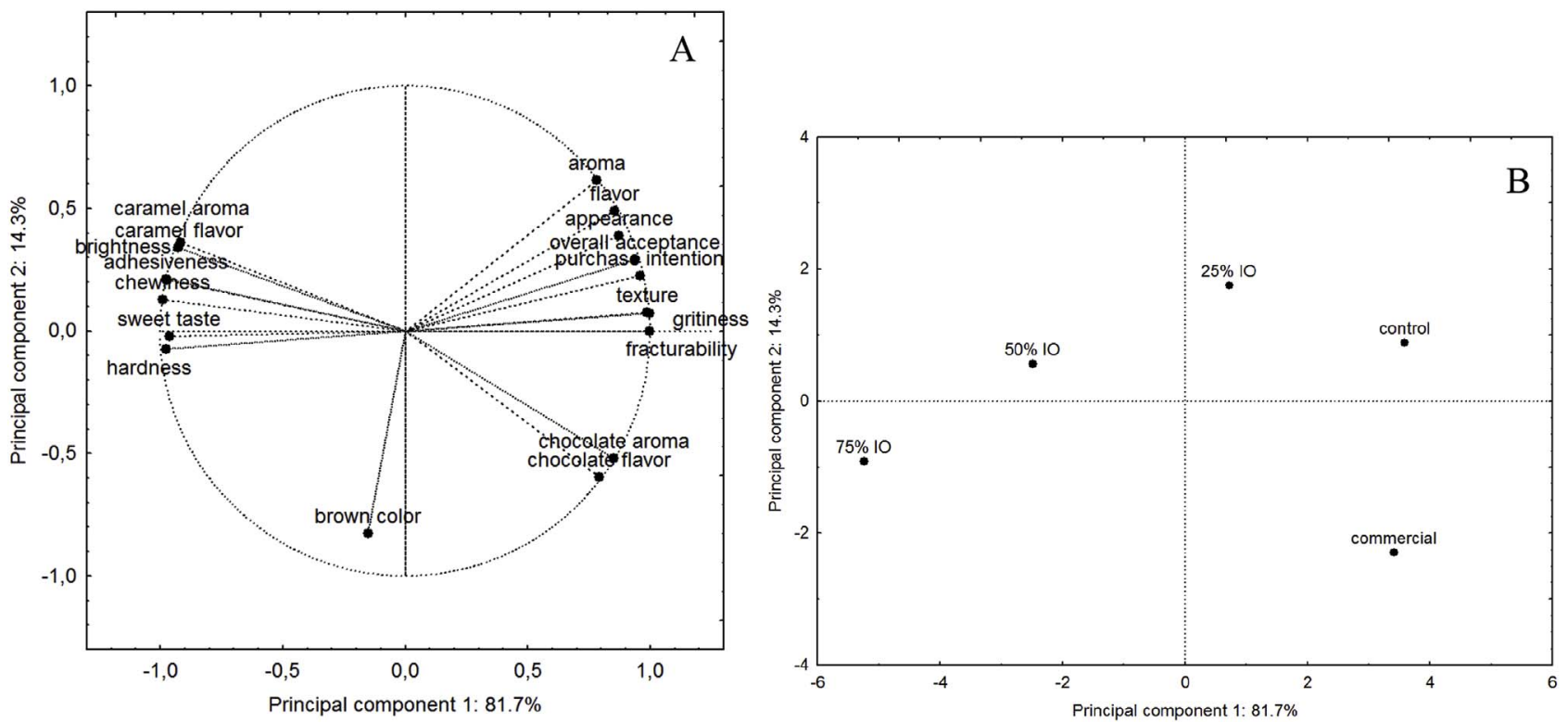

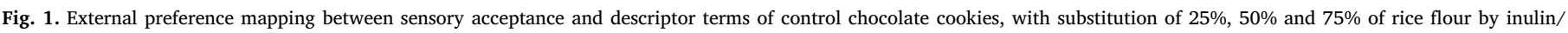
oligofructose (IO) and commercial (A - projection of variables, B - projection of samples). 

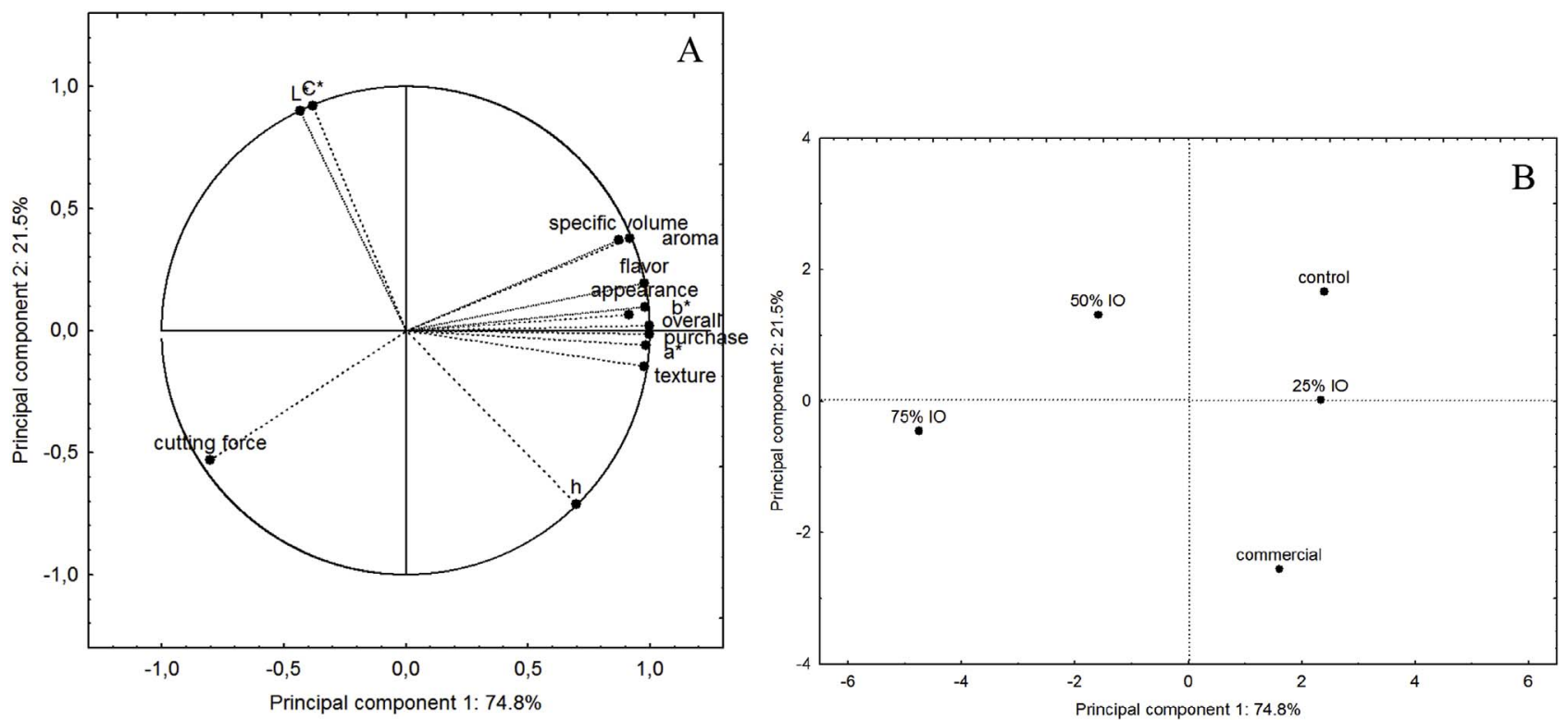

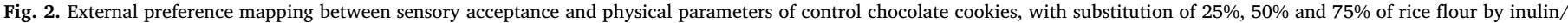
oligofructose (IO) and commercial (A - projection of variables, B - projection of samples).
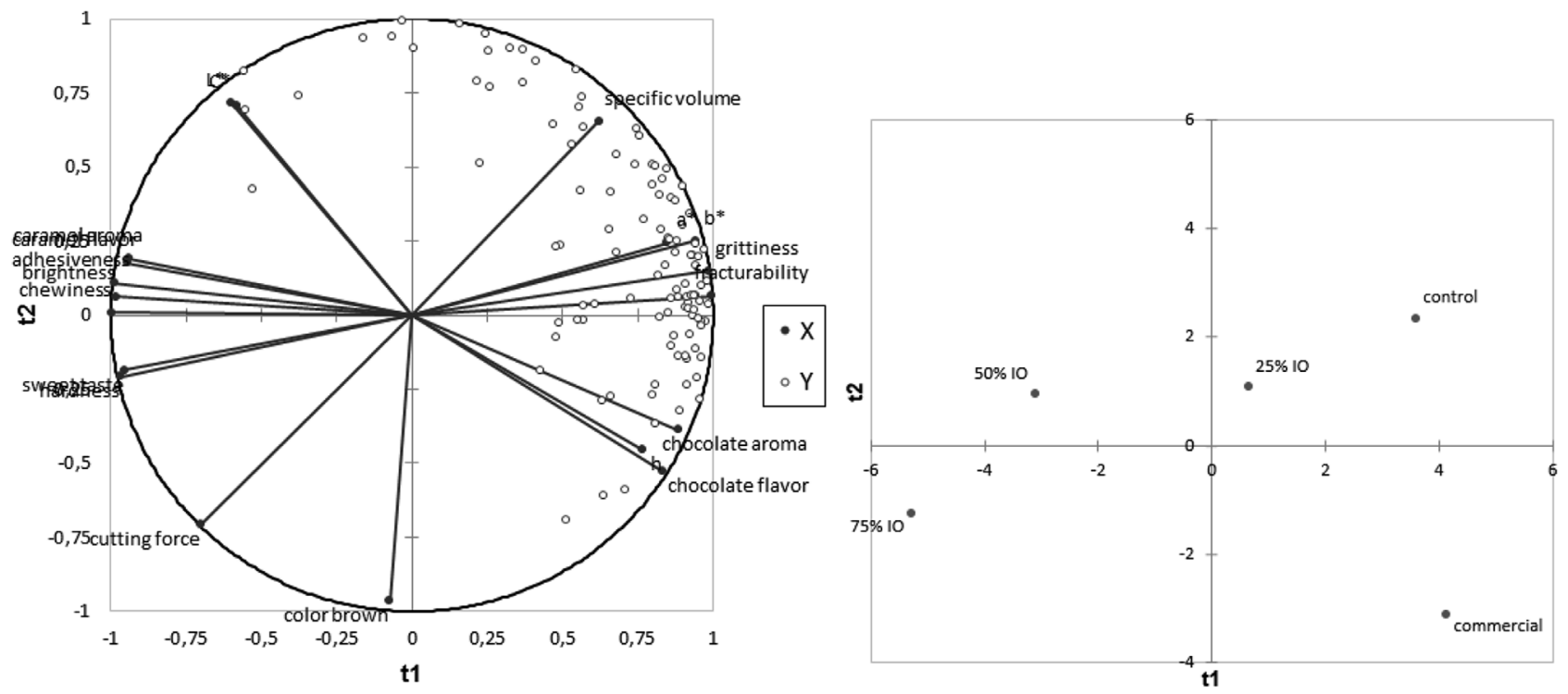

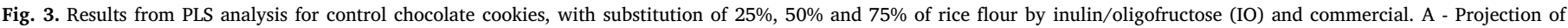
variables ( $\mathrm{X}=$ explanatory variables - descriptor terms and physical parameters; $\mathrm{Y}=$ dependent variables - consumers' acceptance). $\mathrm{B}$ - Projection of samples.

in principal component 1), and another by caramel aroma, caramel flavor, brightness, adhesiveness, chewiness, sweet taste and hardness (factorial charges $\leq-0.7$ in principal component 1 ) (Fig. 1A). Variables in the same group were positively correlated but negatively correlated with variables of the other group. Control chocolate cookies and those with $25 \%$ substitution of rice flour by inulin/oligofructose were characterized by the sensorial acceptance, which was due to the higher intensities of grittiness and fracturability, and lower intensities of caramel aroma, caramel flavor, brightness, adhesiveness, chewiness, sweet taste and hardness (Fig. 1B). At the same time, cookies with $50 \%$ and $75 \%$ of substitution of rice flour by inulin/oligofructose had low acceptance due to higher intensities of caramel aroma, caramel flavor, brightness, adhesiveness, chewiness, sweet taste and hardness. Moreover, the commercial cookie stood out by the chocolate aroma and chocolate flavor. The second principal component was explained only by the brown color (Fig. 1A), but this variable did not describe any cookie (Fig. 1B).
The sensory acceptance also correlates with the physical characteristics of cookies (Fig. 2). The first and second principal components explained, respectively, $74.8 \%$ and $21.5 \%$ of the data variation, totaling $96.3 \%$. The first principal component was explained by sensory acceptance, specific volume, red chromaticity (a*), yellow chromaticity $\left(\mathrm{b}^{*}\right)$ and hue (h), and also by cutting force. The second principal component was explained by the luminosity and chroma (Fig. 2A). The control chocolate cookies and those with $25 \%$ substitution of rice flour by inulin/oligofructose stood out for their sensory acceptance, which were positively correlated with the higher intensities of yellow and red chromaticities and specific volume (Fig. 2B). The cookies with 50\% substitution of rice flour by inulin/oligofructose were highlighted by the luminosity and chroma, cookies with $75 \%$ substitution by the cutting force and commercial cookies by the color hue.

The PLS analysis (Fig. 3) resulted in a cumulated $\mathrm{R}^{2}$ of $77.6 \%$ for two components, and it reiterates the results observed through external preference mappings (Figs. 1 and 2), focusing on the preference by the 
control cookie and the cookie with $25 \%$ of substitution of rice flour by inulin/oligofructose, due to the higher concentration of consumers around these samples. Moreover, the higher acceptance by these samples was influenced by the grittiness, fracturability, specific volume, red and yellow chromaticities of the cookies, as well as observed in the external preference mappings.

\section{Conclusions}

The substitution of rice flour by $25 \%, 50 \%$ and $75 \%$ of inulin/oligofructose resulted in changes in the chemical, physical and sensory properties of cookies, especially when compared to the control and commercial cookies. Cookies with inulin/oligofructose had higher quantities of dietary fibers and can be claimed as gluten-free products. The cookie with $25 \%$ substitution of rice flour by inulin/oligofructose was as well accepted as the control cookie and the commercial cookie for most sensory attributes, overall acceptance and purchase intention. This acceptance was due to the higher intensities of the descriptive terms grittiness and fracturability, yellow and red chromaticities and specific volume, in addition to the low intensities of the descriptive terms caramel aroma, caramel flavor, brightness, adhesiveness, chewiness, sweet taste and hardness, and the low instrumental cutting force. Considering a daily consumption of 3, 2 and 1 servings of glutenfree chocolate cookies with rice flour substitution by 25,50 and $75 \%$ of inulin/oligofructose respectively, the recommended ingestion of $8 \mathrm{~g}$ per day of inulin/oligofructose for enhancing calcium absorption is reached, but always emphasizing that this consumption must be associated with a balanced diet. Moreover, it is important to emphasize that our study allows a new food that favors the increase of the consumption of fibers, and provides a functional ingredient, besides having good sensory acceptance, aspects which are important within the discussion of gluten-free products for celiac individuals.

\section{Acknowledgements}

The authors are grateful for the financial support from FAPESP (Fundação de Amparo à Pesquisa do Estado de São Paulo, grant number 2012/16379-6) and the inulin/oligofructose provided by BENEO.

\section{Appendix A. Supplementary data}

Supplementary data related to this article can be found at http://dx. doi.org/10.1016/j.lwt.2017.12.031.

\section{References}

AACC (2000a). Approved methods of the AACCMethod 10-05(10th ed.). St. Paul: AACC International.

AACC (2000b). Approved methods of the AACCMethod 10-50D(10th ed.). St. Paul: AACC International.

Abrams, S. A., Griffin, I. J., Hawthorne, K. M., Liang, L., Gunn, S. K., Darlington, G., et al. (2005). A combination of prebiotic short-and long-chain inulin-type fructans enhances calcium absorption and bone mineralization in young adolescents. American Journal of Clinical Nutrition, 82, 471-476.

Abrams, S. A., Hawthorne, K. M., Aliu, O., Hicks, P. D., Chen, Z., \& Griffin, I. J. (2007). An inulin-type fructan enhances calcium absorption primarily via an effect on colonic absorption in humans. Journal of Nutrition, 137, 2208-2212.

AOAC (1990). Official methods of analysis of AOAC international (15th ed.). Washington: AOAC International.

BENEO. The BENEO Inulin range. (2016a). http://www.beneo.com/Ingredients/Human Nutrition/Functional_Fibres/Inulin/Accessed 23 May 2017.

Brasil (2003). Agência Nacional de Vigilância Sanitária. RDC n³59, de 23 de dezembro de 2003. Regulamento técnico de porções de alimentos embalados para fins de rotulagem nutricional. Brasília: Diário Oficial da União.

Brasil (2012). Agência Nacional de Vigilância Sanitária. RDC n 54, de 12 de novembro de 2012. Regulamento técnico sobre informação nutricional complementar. Brasília: Diário Oficial da União.

Brennan, C. S., \& Samyue, E. (2004). Evaluation of starch degradation and textural characteristics of dietary fiber enriched biscuits. International Journal of Food Properties, 7, 647-657.

Błońska, A., Marzec, A., \& Błaszczyk, A. (2014). Instrumental evaluation of acoustic and mechanical texture properties of short-dough biscuits with different content of fat and inulin. Journal of Texture Studies, 45, 226-234.

Capriles, V. D., \& Arêas, J. A. G. (2013). Effects of prebiotic inulin-type fructans on structure, quality, sensory acceptance and glycemic response of gluten-free breads. Food \& Function, 4, 104-110.

Capriles, V. D., Soares, R. A. M., Pinto e Silva, M. E. M., \& Arêas, J. A. G. (2009). Effect of fructans-based fat replacer on chemical composition, starch digestibility and sensory acceptability of corn snacks. International Journal of Food Science and Technology, 44, 1895-1901.

Carabin, I. G., \& Flamm, W. G. (1999). Evaluation of safety of inulin and oligofructose as dietary fiber. Regulatory Toxicology and Pharmacology, 30, 268-282.

Ciacci, C., Ciclitira, P., Hadjivassiliou, M., Kaukinen, K., Ludvigsson, J. F., McGough, N., et al. (2015). The gluten-free diet and its current application in coeliac disease and dermatitis herpetiformis. United European Gastroenterology Journal, 3, 121-135.

Codex Alimentarius Commission (2008). Codex standard for foods for special dietary use for persons intolerant to gluten. codex standard 118-1979ftp://ftp.fao.org/codex/Reports/ Alinorm08/al31_26e.pdf, Accessed date: 23 May 2017.

Damásio, M. H., \& Costell, E. (1991). Análisis sensorial descriptive: Generación de descriptors y selección de catadores. Revista de Agroquímica y Tecnología de Alimentos, $31,165-178$.

European Commission (2017). Nutrition claims. https://ec.europa.eu/food/safety/ labelling_nutrition/claims/nutrition_claims_en, Accessed date: 8 November 2017.

Food and Drug Administration (2017). Nutrition facts Label: Dietary fiber - FDA. https:// www.accessdata.fda.gov/scripts/InteractiveNutritionFactsLabel/factsheets/Dietary_ Fiber.pdf, Accessed date: 8 November 2017.

Franck, A. (2002). Technological functionality of inulin and oligofructose. British Journal of Nutrition, 87, 287-291.

Griffin, I. J., Davila, P. M., \& Abrams, S. A. (2002). Non-digestible oligosaccharides and calcium absorption in girls with adequate calcium intakes. British Journal of Nutrition, 87, S187-S191.

Griffin, I. J., Hicks, P. M. D., Heaney, R. P., \& Abrams, S. A. (2003). Enriched chicory inulin increases calcium absorption mainly in girls with lower calcium absorption. Nutrition Research, 23, 901-909.

Handa, C., Goomer, S., \& Siddhu, A. (2011). Pilot-scale technology development, nutritional and consumer assessment of whole-multigrain cookies as influenced by fructan inclusion. Journal of Food Science, 76, S198-S202.

Huebner, J., Wehling, R. L., Parkhurst, A., \& Hutkins, R. W. (2008). Effect of processing conditions on the prebiotic activity of commercial prebiotics. International Dairy Journal, 18, 287-293.

Jothi, J. S., Hashem, S., Rana, M. R., Rahman, M. R. T., \& Shams-Ud-Din, M. (2014). Effect of gluten-free composite flour on physico-chemical and sensory properties of cracker biscuits. Journal of Scientific Research, 6, 521-530.

Kamycheva, E., Goto, T., \& Camargo, C. A. (2016). Celiac disease is associated with reduced bone mineral density and increased FRAX scores in the US National Health and Nutrition Examination Survey. Osteoporosis International, 27, 1-10.

Ktenioudaki, A., \& Gallagher, E. (2012). Recent advances in the development of high-fibre baked products. Trends in Food Science \& Technology, 28, 4-14.

Laguna, L., Salvador, A., Sanz, T., \& Fiszman, S. M. (2011). Performance of a resistant starch rich ingredient in the baking and eating quality of short-dough biscuits. $L W T$ Food Science and Technology, 44, 737-746.

Laguna, L., Varela, P., Salvador, A., Sanz, T., \& Fiszman, S. M. (2012). Balancing texture and other sensory features in reduced fat short-dough biscuits. Journal of Texture Studies, 43, 235-245.

Laureati, M., Giussani, B., \& Pagliarini, E. (2012). Sensory and hedonic perception of gluten-free bread: comparison between celiac and non-celiac subjects. Food Research International, 46, 326-333.

Maache-Rezzoug, Z., Bouvier, J. M., Allaf, K., \& Patras, C. (1998). Effect of principal ingredients on rheological behaviour of biscuit dough and on quality of biscuits. Journal of Food Engineering, 35, 23-42.

MacFie, H. J., Bratchell, N., Greenhoff, K., \& Vallis, L. V. (1989). Designs to balance the effect of order of presentation and first-order carry-over effects in hall tests. Journal of Sensory Studies, 4, 129-148.

McCleary, B. V., \& Rossiter, P. (2004). Measurement of novel dietary fibers. Journal of the Association of Official Analytical Chemists, 87, 707-717.

Meilgaard, M., Civille, G. V., \& Carr, B. T. (2007). Sensory evaluation techniques (4th ed.). Boca Raton: CRC Press.

Morris, C., \& Morris, G. A. (2012). The effect of inulin and fructo-oligosaccharide supplementation on the textural, rheological and sensory properties of bread and their role in weight management: A review. Food Chemistry, 133, 237-248.

Moskowitz, H. R. (1983). Product testing and sensory evaluation of foods. Westport: Food \& Nutrition Press.

Panteris, V., \& Karamanolis, D. G. (2005). Gluten enteropathy: Current views on diagnosis and treatment. Annals of Gastroenterology, 18, 402-419.

Pareyt, B., Brijs, K., \& Delcour, J. A. (2010). Impact of fat on dough and cookie properties of sugar-snap cookies. Cereal Chemistry, 87, 226-230.

Pomeranz, Y., Shogren, M., Finney, K. F., \& Bechtel, D. B. (1977). Fibre in breadmakingeffects on functional properties. Cereal Chemistry, 54, 25-41.

Prosky, L., Asp, N. G., Schweizer, T. F., DeVries, J. W., \& Furda, I. (1988). Determination of insoluble, soluble and total dietary fiber in foods and foods products: Scandinavian Journal of Gastroenterology intralaboratory study. Journal of the Association of Official Analytical Chemists, 71, 1017-1023.

BENEO. Increase calcium absorption. (2016b). http://www.beneo.com/Benefits/ Healthy Aging/Accessed 23 May 2017.

Rodriguez-Garcia, J., Laguna, L., Puig, A., \& Hernando, I. (2013). Effect of fat replacement by inulin and textural and structural properties of short dough biscuits. Food Bioprocess Technology, 6, 2739-2750. 
Ronda, F., Gómez, M., Blanco, C. A., \& Caballero, P. A. (2005). Effects of polyols and nondigestible oligosaccharides on the quality of sugar-free sponge cakes. Food Chemistry, 90, 549-555.

Ronkart, S. N., Paquot, M., Fougnies, C., Deroanne, C., \& Blecker, C. S. (2009). Effect of water uptake on amorphous inulin properties. Food Hydrocolloids, 23, 922-927.

Sapone, A., Bai, J. C., Ciacci, C., Dolinsek, J., Green, P. H. R., Hadjivassiliou, M., et al (2012). Spectrum of gluten-related disorders: Consensus on new nomenclature and classification. BMC Medicine, 10, 1-12.

Shoaib, M., Shehzad, A., Omar, M., Rakha, A., Raza, H., Sharif, H. R., et al. (2016). Inulin: Properties, health benefits and food applications. Carbohydrate Polymers, 147, 444-454.

Silva, T. F., \& Conti-Silva, A. C. (2016). Preference mappings for gluten-free chocolate cookies: Sensory and physical characteristics. Nutrition \& Food Science, 46, 374-387.

Stone, H., \& Sidel, J. (2004). Sensory evaluation practices (3rd ed.). New York: Academic Press.
Sudha, M. L., Vetrimani, R., \& Leelavathi, K. (2007). Influence of fibre from different cereals on the rheological characteristics of wheat flour dough and on biscuit quality. Food Chemistry, 100, 1365-1370.

Tárrega, A., \& Costell, E. (2006). Effect of inulin addition on rheological and sensory properties of fat-free starch-based dairy desserts. International Dairy Journal, 16, 1104-1112.

Tuorila, H., \& Monteleone, E. (2009). Sensory food science in the changing society: Opportunities, needs, and challenges. Trends in Food Science \& Technology, 20, 54-62.

Volpini-Rapina, L. F., Sokei, F. R., \& Conti-Silva, A. C. (2012). Sensory profile and preference mapping of orange cakes with addition of prebiotics inulin and oligofructose. Lebensmittel-Wissenschaft und -Technologie- Food Science and Technology, 48, 37-42.

Wang, Y. (2009). Prebiotics: Present and future in food science and technology. Food Research International, 42, 8-12.

Wang, J., Rosell, C. M., \& Barber, C. B. (2002). Effect of the addition of different fibres on wheat dough performance and bread quality. Food Chemistry, 79, 221-226. 